\title{
28 Research Soure \\ Identifying Suitable Areas for Common Bottlenose Dolphins in Anthropized Waters
}

\section{Guilherme Maricato}

Universidade do Estado do Rio de Janeiro

\section{Rodrigo Tardin}

Universidade Federal do Rio de Janeiro

\section{Liliane Lodi}

Instituto Mar Adentro

\section{Leonardo L. Wedekin}

Socioambiental Consultores Associados

\section{Fábio G. Daura-Jorge}

Universidade Federal de Santa Catarina

Israel Maciel

Universidade do Estado do Rio de Janeiro

Tatiana F. Maria ( $\nabla$ tatiana_fabricio@yahoo.com.br )

Universidade Federal do Estado do Rio de Janeiro

\section{Maria Alice S. Alves}

Universidade do Estado do Rio de Janeiro

\section{Research Article}

Keywords: Species distribution modeling, habitat use, cetacean, degree of residence, human impact, Brazil

Posted Date: January 18th, 2022

DOI: https://doi.org/10.21203/rs.3.rs-1250927/v1

License: (c) (i) This work is licensed under a Creative Commons Attribution 4.0 International License. Read Full License 


\section{Abstract}

Understanding the processes that determine the occurrence of species, especially for those exposed to human activities, is the key to appropriate management. Despite Tursiops truncatus being well-studied worldwide, information about transient groups of this common bottlenose dolphins and how groups are exposed to human activities is lacking. Here, we modelled and mapped how the environment and human activities drives bottlenose dolphin habitat suitability, and residence patterns in an anthropized area of the Southwestern Atlantic Ocean. We ran 300 distribution models, including six algorithms, and generated an ensemble model to predict the habitat suitability of the species. In parallel, we used photo-identification techniques to evaluate dolphins' degree of residence pattern. Primary productivity, seabed slope and port activities explained dolphins' habitat suitability. The most suitable areas for bottlenose dolphins included coastal waters, nearby port complexes and shipping routes. We also identified a low degree of residence in Cabo Frio and Rio de Janeiro city waters, but calves were constantly sighted there, indicating an important area for caring and nursing. The high overlap between the dolphins' most suitable areas and human activities, such as ports, vessel traffic and fisheries spots, plus the presence of calves in these areas, highlights the need for safeguard measurements to protect these animals from threats. In addition, our results may be used to support management decisions, such as fisheries regulations and the creation of new marine protected areas to conserve critical habitats of this species.

\section{Introduction}

Distribution studies are critical to assess the effects of the environment and human activities on several species (Morris and Doak 2002; Rodrigues et al. 2006). Species Distribution Models (SDM) have been increasingly used to determine the potential distribution and identify suitable habitats for conservation purposes (Guisan et al. 2017). However, the distribution of marine organisms is not well studied as it occurs for terrestrial organisms (Redfern et al. 2006, Robinson et al. 2011). In addition, the distribution of these organisms is mainly explained based exclusively on environmental variables (e.g. di Tullio et al. 2016; McBride-Kebert et al. 2019; de Rock et al. 2019) neglecting the importance of human activities in affecting species distributions.

For years, studies of marine species with high movement ability have been challenging for researchers (Redfern et al. 2006). Marine mammals, like dolphins, use to live in open and fluid environments, with few or no physical barriers to limit their access to resources, such as highly mobile prey (Sims et al. 2008; MeloMerino et al. 2020). Their distribution changes over time due to changes in their biological and ecological requirements (Forcada 2018). As a result, these animals used to have higher mobility and larger home ranges when compared to terrestrial mammals (Tucker et al. 2014). Eventually, individuals or entire populations can have a high degree of association with specific areas, which is in general related to resource availability, leading to repeatedly revisit these areas or constantly use them (e.g. Nathan et al. 2008; Passadore et al. 2018; Akkaya Baş et al. 2019).

The common bottlenose dolphin (Tursiops truncatus), hereafter called bottlenose dolphin, is a cosmopolitan species found in coastal and oceanic environments (e.g. Milmann et al. 2016; Zanardo et al. 2017; Tardin et 
al. 2020). As top predators, this species is susceptible to several impacts on the environment, such as the accumulation of contaminants in high concentrations, reflecting the health of the ecosystem (Smith and Gangolli 2002). The species has ecological plasticity, i.e., worldwide populations vary considerably in terms of habitat use, residence pattern, behavior, and diet (Fruet et al. 2011; Lodi et al. 2014; Tardin et al. 2020; Carmen et al. 2021; Pace et al. 2021). However, information about some populations is still scarce. Although this species is found on almost the entire Brazilian coast (Lodi et al. 2017), most studies analyzed populations with temporary or permanent residence at a local scale (Simões-Lopes \& Fabian 1999, Fruet et al. 2011). Recently, two distinct subspecies, a coastal and an offshore one, were recognized through genetics and morphological evidence in the Southwestern Atlantic (Costa et al. 2016; Simões-Lopes et al. 2019).

In the present study, we focus on the offshore ecotype, Tursiops truncatus truncatus, which is the unique subspecies that occurs in the study area, Rio de Janeiro State waters (Simões-Lopes et al. 2019). These waters are surrounded by the most populated area in Latin America, housing an important industrial pole, including oil and gas exploitation, and several port complexes (IBGE 2010; ANTAQ 2021). Due to the cumulative nature of different activities and their unique characteristics, such as habitat variability and threatened species, this area is considered a top conservation priority in Brazil (Magris et al. 2021). To support appropriate safeguard plans for bottlenose dolphins, we aimed to (i) model how the environment and human activities drives bottlenose dolphins habitat suitability, (ii) map the modelled suitable and unsuitable areas and (iii) analyze the individuals' residence pattern. Considering that these animals have high energy requirements, we hypothesized that oceanographic characteristics related to prey distribution are the main driver influencing the bottlenose dolphin habitat suitability.

\section{Material And Methods}

\subsection{Study area}

Our study area is defined by the geopolitical boundaries of the Rio de Janeiro State, from the coastline to the territorial sea of 200 nautical miles (Fig. 1), in the Southeastern Brazilian coast located on the Southwestern Atlantic Ocean (SWAO). It comprises part of two sedimentary basins: Campos Basin and Santos Basin, both explored by the oil and gas industry, with vessel traffic and exploration, drilling, and extraction activities (ANP 2021). Industrial fish activities are also common in the area comprising approximately 50,000 t of fisheries resources captured per year (Fiperj 2020). Two subareas were chosen, the Cabo Frio coast, comprised the municipalities of Arraial do Cabo, Cabo Frio, and Búzios, and the Rio de Janeiro coast, comprised the municipalities of Rio de Janeiro and Niterói (Fig. 1). There, we carried out systematic photo-identification surveys that were later used to investigate residence patterns.

The Cabo Frio subarea (CF) has a narrow and irregular continental shelf showing depressions and steep slopes and the $100 \mathrm{~m}$ isobath is found at a maximum distance of $10 \mathrm{~km}$ from the coast (Duarte and Viana 2007; Reis et al. 2013). The warm and oligotrophic Tropical Water flows southward carried by the Brazil Current, but during springer and summer, the South Atlantic Central Water recurrently emerges due to a winddriven upwelling, resulting in high primary and fish productivity (Carbonel 1998; Mazzoil et al. 2008). 
The Rio de Janeiro subarea (RJ) has a more extensive continental shelf and consequently a less pronounced slope than CF. The $100 \mathrm{~m}$ isobath is located $80 \mathrm{~km}$ from the coast (Reis et al. 2013). This subarea is surrounded by of the most populous cities in Latin America, Rio de Janeiro city, having six million inhabitants (IBGE 2010). This subarea is continuously exposed to several human threats such as overfishing, submarine outfalls, and eutrophic waters from Guanabara Bay (Carreira and Wagener 1998; Rangel et al. 2007; Tubino et al. 2007; Amorim and Monteiro-Neto 2016).

\subsection{Distribution}

\subsubsection{Data collection}

We compiled occurrence records of common bottlenose dolphins from several sources which included primary and secondary data from 1983 to 2021 (Supplementary Table 1). Environmental layers (minimum, mean and maximum) for our study area were obtained from three different public databases: Bio-Oracle (Assis et al. 2018), Global Marine Datasets for Species Distribution Modelling and Environment Visualisation (Basher et al. 2018) and Ocean Climate Layers for Marine Spatial Ecology (Sbrocco and Barber 2013) at 5 arcminutes resolution. Port activity layers were obtained from the ocean-based pollution layer (Halpern et al. 2015) at 30 arcseconds resolution (Table 1). All layers were standardized for 5 arcminutes resolution and used as explanatory variables for the bottlenose dolphin habitat suitability.

Table 1

Data source of environmental and anthropogenic layers used as explanatory variables to model the suitable areas for common bottlenose dolphin (Tursiops truncatus truncatus) occurrence in Rio de Janeiro State.

\begin{tabular}{|ll|}
\hline Layers & References \\
\hline Environmental & \\
\hline Bathymetry & MARSPEC \\
\hline Current velocity (minimum, mean and maximum) & Bio-ORACLE \\
\hline Distance to coast & GMED \\
\hline Primary productivity (minimum, mean and maximum) & Bio-ORACLE \\
\hline Salinity & Bio-ORACLE \\
\hline Sea surface temperature (minimum, mean and maximum) & Bio-ORACLE \\
\hline Seabed slope & GMED \\
\hline Anthropogenic & \\
\hline Port activities (ocean-based pollution) & Halpern et al. \\
\hline
\end{tabular}

\subsubsection{Data analyzes}

We carried out all the analyzes in the R environment ( $R$ Core Team 2021) and used the R package 'biomod2' (Thuiller et al. 2020) to generate the Species Distribution Models. To avoid spatial autocorrelation, we 
randomly filtered occurrence records within a radius of $9.2 \mathrm{~km}$ ( 5 arcminutes) using the 'spThin' package (Aiello-Lammens et al. 2015). We checked multicollinearity among the explanatory variables using the 'usdm' package (Naimi et al. 2014) and those with Variance Inflation Factor (VIF) $>3$ were excluded from the model (Zuur et al. 2010).

Since it was not possible to obtain true absence data, we randomly generated five sets of 1000 pseudoabsences. We used six algorithms for two types of data requirements: presence-absence models using regression (Generalized Linear Models - GLM and Generalized Additive Models - GAM), boosting (Random Forest - RF and Generalized Boosting Model - GBM), discrimination techniques (Flexible Discriminant Analysis - FDA), and presence-background models using Maximum Entropy models - MaxEnt (see Guisan et al. 2017) to a brief explanation of each algorithm). For model calibration, we used $70 \%$ of records for training and $30 \%$ for testing using cross-validation techniques at a constant prevalence at 0.5 (Guisan et al. 2017). Each algorithm was replicated ten times and the importance of each variable was retrieved running ten permutations using the 'get_variables_importance' function of the 'biomod2' package (Thuiller et al. 2020). This test shuffles a variable in the dataset and compares the predictions of the reference model and the shuffled model via Pearson's correlation. The higher the correlation index, the more influence the variable has on the model (Thuiller et al. 2020).

We generated response curves for bottlenose dolphin habitat suitability as a function of each explanatory variable included in our final models (Supplementary Fig. S1). The metric used for the evaluation of each model was the Area Under the Curve (AUC) from the Receiver Operating Characteristic (ROC) (Fielding and Bell 1997). All replicates with AUC $>0.7$ were selected and aggregated for a final ensemble model using weighted-by-AUC mean (pAUC) (Araújo and New 2007). To include a measure of uncertainty, which is suggested for any SDMs (Zurell et al. 2020), we generated a committee averaging map that indicates the coefficient of variation of the algorithms (Supplementary Fig. S2).

\subsection{Residence pattern}

We investigated residence pattern based on photo-identification data from long-term cetacean monitoring projects conducted by the Laboratório de Bioacústica e Ecologia de Cetáceos, Projeto Baleias \& Golfinhos do Rio and Projeto Ilhas do Rio, and by large scale scientific cruises, such as Projeto de Monitoramento de Cetáceos da Bacia de Santos. The photo-identification technique consisted of taking dorsal fin images during surveys and comparing the natural marks (i.e., nicks, notches, scars) in each dorsal fin by photoidentification protocols that allowed a reliable individual identification (Hammond et al. 1990). Then, for identified individuals, we calculated the individual residence index as the number of days individual dolphins were sighted divided by (i) the number of days of total effort and (ii) the number of days of effort from the first sighting to the last one. We also calculated residence as (iii) the number of seasons individual dolphins were sighted divided by the number of seasons of effort.

These residence indices were standardized, and individual dolphin identified was categorized in three levels (low, medium or high, set out by us according to the data) through the analysis of Agglomerative Hierarchical Clustering using the Ward distance method and the squared Euclidean distance measure. This analysis generates a matrix of dissimilarity through pre-established parameters. We calculated the 
cophenetic correlation coefficient to evaluate whether the analysis distortion was significant, assuming a suitable clustering of the data when the value was above 0.7 (Rohlf 1970).

\section{Results}

The filtering technique retained 62 records from 445. After multicollinearity inspection, six of the 14 explanatory variables were selected: minimum and maximum current velocity (CURmin and CURmax, respectively), port activities (port), minimum primary productivity (PPmin), seabed slope (slope), and minimum sea surface temperature (SSTmin) (Supplementary Table 2).

For the final ensemble model ( $\mathrm{pAUC}>0.7$ ), we considered 207 out of 300 models. Algorithms' performances varied and, in general, FDA had the lowest pAUC values (mean $=0.76$ ) and GBM the highest $(0.81)$ (Table 2). The PPmin (0.65), slope (0.18), and port (0.10) were the most important variables (Table 2). Overall, bottlenose dolphin habitat suitability had a non-linear positive relationship with port, a negative relationship with slope, and was higher in average values of PPmin (Supplementary Fig. S1). The most suitable areas for the species distribution were in shallow waters within the continental shelf. The highest suitability values were in the coastal area displayed in the East-West direction, including the two subareas (CF and RJ) and three bays: Ilha Grande, Sepetiba, and Guanabara (Fig. 2).

Considering CF and RJ subareas, a total of 614 individuals were cataloged between 2011 and 2018. Fiftyseven (9.3\%) individuals were recaptured at least once and included in the residence analysis. Of these, 39 individuals had a low residence degree (68.4\%), seven had a medium degree $(12.3 \%)$ and 11 had a high degree (19.3\%) (Supplementary Fig. 3). The cophenetic correlation coefficient of 0.73 indicated that the dendrogram was well clustered.

\section{Discussion}

We showed that the offshore bottlenose dolphins (Tursiops truncatus truncatus) are, in general, transient in Rio de Janeiro waters (low degree of residence), but with a small subset of individuals with medium or high degree of residence in specific areas. These bottlenose dolphins also occur in coastal areas and continental shelf waters, up to the slope, likely influenced by environmental conditions and human activities. We found that the most suitable areas for these dolphins occur in high primary productivity sites, along the continental shelf, and in more gentle slopes, from shallow water, less than $50 \mathrm{~m}$ deep. Shallow waters tend to be more productive, presenting a greater abundance of fishes (Fiperj 2020), which are typical prey of these dolphins. Indeed, the predicted suitable areas for bottlenose dolphins, including CF and RJ subareas. These are surrounded by fishing landing ports that land more than $90 \%$ of the local fishing resources caught in the study area (Fiperj 2020) reinforcing that these sites likely have high prey availability.

Primary productivity was an important predictor to explain suitable areas for bottlenose dolphins. However, bottlenose dolphins were not usually sighted in regions with the highest values for primary productivity, such as Ilha Grande, Sepetiba and Guanabara bays. These values were equivalent to those usually found in eutrophic waters (e.g. Marins et al. 2010; Aguiar et al. 2011; Castelo et al. 2021). The absence of bottlenose 
dolphins in those areas could be associated with the co-occurrence of other dolphins' species. Indeed, these bays are also inhabited by resident populations of Guiana dolphins, Sotalia guianensis (e.g. Ribeiro-Campos et al. 2021). An aggressive interaction between bottlenose and Guiana dolphins were reported in Baía Norte, Southern Brazil (Wedekin et al. 2004), an area where both species overlap their niches by sharing consumptions of demersal mullet species; therefore, it is suggested that potential interspecific competition between both dolphin populations may be a limiting factor for the occurrence of bottlenose dolphins (Teixeira et al. 2021) which avoid these areas even if the habitat is suitable for their occurrence as indicated by our results. On the other hand, bottlenose dolphins are usually sighted outside the three bays, such as CF and RJ subareas (e.g. Tardin et al. 2013, 2019; Laporta et al. 2017). The frequent occurrence of groups in these two subareas, most of them including calves (87.5\%), suggests that both subareas may be important for feeding and breeding bottlenose dolphins.

Considering CF subarea, bottlenose dolphins are already known to occur primarily in shallow and productive areas (Tardin et al. 2019). On a larger scale, on the shelf break of South and Southeast regions, the frequency of sightings is greater in areas close to the $500 \mathrm{~m}$ isobath than in deeper waters (di Tullio et al. 2016), but worldwide bottlenose dolphins show plasticity in habitats used. This species tends to use shallow water with higher primary productivity either in sheltered or open waters with gentle slopes occurring in Australia, Namibia, Spain, and the United States (Cañadas et al. 2002; Zanardo et al. 2017; McBride-Kebert et al. 2019; de Rock et al. 2019). However, this species is also found in steeper slopes with high primary productivity caused by upwelling in shelf break or as barriers during feeding tactics in shallow habitats (Cañadas et al. 2002; McBride-Kebert et al. 2019).

Residence patterns in a specific area also vary among populations worldwide, from high (e.g. Simões-Lopes and Fabian 1999; Laporta et al. 2017; Carmen et al. 2021; Bennington et al. 2021) to low (e.g. Zolman 2002; Balmer et al. 2008; Akkaya Baş et al. 2019; Pace et al. 2021). Low residence patterns can indicate that the species use larger habitats than the studied area (Zanardo et al. 2016; Cobarrubia-Russo et al. 2019), while a high residence pattern to specific locations may suggest critical habitats for vital activities (Simões-Lopes and Fabian 1999; Ingram and Rogan 2002). Indeed, large range movements (from 700 to ca. 1.700 km) were observed for bottlenose dolphins tagged with satellite tags or photo-identified in Brazil (Cremer et al. 2018). Thus, it is likely that the individuals analyzed in the present study belong to a large population and groups remain in a certain area for short-term periods or regularly visit it to feed or breed. An individual variance in terms of residence may suggest complex habitat, social or population structures (Zolman 2002; Blasi and Boitani 2014). Residence in a specific area may be linked to the high availability of food resources and low predation risks (Knip et al. 2012; Habel et al. 2016). On the other hand, resident individuals tend to be more exposed to local threats (Warkentin and Hernández 1996; Atkins et al. 2016). Even those dolphins with low residence patterns might be exposed to local threats in our study area. The most suitable areas for the species, for example, are areas close to port complexes and shipping routes. These areas are surrounded by four port complexes (located on Campos municipality, Guanabara, Sepetiba and Ilha Grande bays), and are affected by nearby ports along the coast (located on Macaé, Búzios, Cabo Frio municipalities and Guaíba Island) (ANTAQ 2021). There is also high vessel traffic associated with oil and gas exploration occurring in the Campos and Santos basins (ANP 2021). The effects of port complexes and related activities, such as vessel traffic, on dolphins' populations are well-reported worldwide (e.g. Halpern et al. 
2015; Walker et al. 2019). Collisions of dolphins with vessels or their propellers, for example, may cause mutilation and even the death of individuals (van Waerebeek et al. 2007; Schoeman et al. 2020). Noisy areas, such as those near port complexes and shipping routes, may also change dolphin behavior and acoustic repertoire, cause acoustic masking, and lead to temporary or permanent habitat abandonment (Guerra et al. 2014; Marley et al. 2017; Erbe et al. 2019). Additionally, as aforementioned, we found that the highest suitable areas for bottlenose dolphins overlap with important fisheries activities (Fiperj 2020) increasing bycatch risks.

Besides, these suitable areas also have high levels of contaminants (Vidal et al. 2020), which may cause various adverse effects on cetaceans, such as contamination of calves crossing the placenta or through lactation, and immunosuppression of both calves and adults, which may result in skin diseases and even death (Moura et al. 2009; Bossart 2011; Vidal et al. 2020). Therefore, individuals occurring in this area may be under all these risks.

Understanding residence patterns together with the predictions of suitable habitats can contribute to safeguarding critical areas for these dolphins. Our study identified the most suitable habitats for bottlenose dolphins in an area with multiple human activities that may expose them to several different impacts. We also found that dolphins vary in how they use the area, suggesting complex social or populational structures. By mapping these critical areas and characterizing how dolphins use them, our findings may support additional and more effective conservation actions. For instance, a creation of MPAs to better manage local human activities, and then protect critical habitats for this important top predator since the MPAs network along Rio de Janeiro State does not encompass most of the highest suitable sites for bottlenose dolphins. Moreover, effective management of fisheries focusing on the protection of the ecosystem and reducing the bycatch of this species and any other marine species is urgently needed.

\section{Declarations}

Acknowledgments We would like to thank Laboratório de Bioacústica e Ecologia de Cetáceos, Projeto Baleias \& Golfinhos do Rio de Janeiro, Projeto Ilhas do Rio, Projeto de Monitoramento de Cetáceos and Projeto Talude for support in data collecting and analyzes. We thank Petrobras for kindly authorizing the data use from Projeto de Monitoramento de Cetáceos na Bacia de Santos.

Author contributions Study conception and design were performed by GM, RT, TM and MA. Data collection and analyzes were performed by GM, RT, LL, LW, FD and IM. The first draft of the manuscript was written by GM and all authors commented on previous versions of the manuscript. All authors read and approved the final manuscript

Funding This study was financed in part by the Coordenação de Aperfeiçoamento de Pessoal de Nível Superior - Brasil (CAPES) - Finance Code 001. Laboratório de Bioacústica e Ecologia de Cetáceos was funded by Edital Universal / Conselho Nacional de Desenvolvimento Científico e Tecnológico (CNPq) (number 479348/2010-3) and by Fundação Grupo Boticário de Proteção à Natureza (number 0997/2013-2). Projeto Baleias \& Golfinhos do Rio de Janeiro is accomplished by Instituto Mar Adentro and funded by Programa Costa Atlântica / Fundação SOS Mata Atlântica (2013, 2016-2017 e 2019) and by Programa 
Marinho / WWF-Brasil (2016-2017, number CPT 00776-2016). Projeto Ilhas do Rio is accomplished by Instituto Mar Adentro, funded by Petrobras (concession number: phase II - 6000.0086840.13.2 and phase III - 5850.0106133.17.2), and with technical curation by WWF-Brasil and funded by Associação IEP e JGP (phase IV). Projeto de Monitoramento de Cetáceos is a monitoring program required by Brazil's federal environmental agency, IBAMA, for the environmental licensing process of the oil production and transport by Petrobras at the Santos Basin pre-salt province (process number 02001.114279/2017-80, ACCTMB number 657/2015). Fábio G. Daura-Jorge received research grants from CNPq (308867/2019-0) and from CAPES (88887.374128/2019-00). Research grants to Maria Alice S. Alves were provided by CNPq research grant (PQ process \#306.579/2018-9).

Data availability Part of the data used in this study can be found at https://sispmcprd.petrobras.com.br/sispmc. Data not available on the previous website can be requested from the corresponding author.

Conflict of interest The authors declare no competing interests.

Ethics approval This is an observational study and no ethical approval is required.

\section{References}

1. Aguiar VM de C, Neto JAB, Rangel CM (2011) Eutrophication and hypoxia in four streams discharging in Guanabara Bay, RJ, Brazil, a case study. Marine Pollution Bulletin 62:1915-1919. doi: 10.1016/j.marpolbul.2011.04.035

2. Aiello-Lammens ME, Boria RA, Radosavljevic A, Vilela B, Anderson RP (2015) spThin: an R package for spatial thinning of species occurrence records for use in ecological niche models. Ecography 38:541545. doi: 10.1111/ecog.01132

3. Akkaya Baş A, Öztürk B, Amaha Öztürk A (2019) Encounter rate, residency pattern and site fidelity of bottlenose dolphins ( Tursiops truncatus ) within the Istanbul Strait, Turkey. Journal of the Marine Biological Association of the United Kingdom 99:1009-1016. doi: 10.1017/S0025315418000577

4. Amorim RB, Monteiro-Neto $C$ (2016) Marine protected area and the spatial distribution of the gill net fishery in Copacabana, Rio de Janeiro, RJ, Brazil. Brazilian Journal of Biology 76:1-9. doi: 10.1590/1519-6984.06614

5. ANP (2021) Agência Nacional do Petróleo, Gás Natural e Biocombustíveis (ANP). https://www.gov.br/anp/pt-br. Accessed 26 Apr 2021

6. ANTAQ (2021) Agência Nacional de Transportes Aquaviários (ANTAQ). https://www.gov.br/antaq/ptbr. Accessed 26 Apr 2021

7. Araújo MB, New MG (2007) Ensemble forecasting of species distributions. Trends in Ecology \& Evolution 22:42-47. doi: 10.1016/j.tree.2006.09.010

8. Assis J, Tyberghein L, Bosch S, Verbruggen H, Serrão EA, de Clerck O (2018) Bio-ORACLE v2.0: Extending marine data layers for bioclimatic modelling. Global Ecology and Biogeography 27:277-284. doi: $10.1111 /$ geb.12693 
9. Atkins S, Cantor M, Pillay N, Cliff G, Keith M, Parra G (2016) Net loss of endangered humpback dolphins: integrating residency, site fidelity, and bycatch in shark nets. Marine Ecology Progress Series 555:249-260. doi: 10.3354/meps11835

10. Balmer BC, Wells RS, Nowacek SM, Nowacek DP, Schwacke LH, Mclellan WA, Scharf SF, Rowles TK, Hansen LJ, Spradlin TR, Pabst DA (2008) Seasonal abundance and distribution patterns of common bottlenose dolphins (Tursiops truncatus) near St. Joseph Bay, Florida, USA. Journal of Cetacean Research and Management 10:157-167.

11. Basher Z, Bowden D, Costello M (2018) Global Marine Environment Datasets (GMED). In: World Wide Web electronic. http://gmed.auckland.ac.nz.

12. Bennington S, Rayment W, Currey R, Oldridge L, Henderson S, Guerra M, Brough T, Johnston D, Corne C, Johnson D, Slooten L, Dawson S (2021) Long-term stability in core habitat of an endangered population of bottlenose dolphins (Tursiops truncatus): Implications for spatial management. Aquatic Conservation: Marine and Freshwater Ecosystems 31:665-676. doi: 10.1002/aqc.3460

13. Blasi MF, Boitani L (2014) Complex social structure of an endangered population of bottlenose dolphins (Tursiops truncatus) in the Aeolian Archipelago (Italy). PLoS ONE 9:e114849. doi: 10.1371/journal.pone.0114849

14. Bossart GD (2011) Marine Mammals as Sentinel Species for Oceans and Human Health. Veterinary Pathology 48:676-690. doi: 10.1177/0300985810388525

15. Cañadas A, Sagarminaga R, García-Tiscar S (2002) Cetacean distribution related with depth and slope in the Mediterranean waters off southern Spain. Deep Sea Research Part I: Oceanographic Research Papers 49:2053-2073. doi: 10.1016/S0967-0637(02)00123-1

16. Carbonel C (1998) Modelling of upwelling in the coastal area of Cabo Frio (Rio de Janeiro - Brazil). Revista Brasileira de Oceanografia 46:01-17. doi: 10.1590/S1413-77391998000100001

17. Carmen M, Berrow SD, O’Brien JM (2021) Foraging Behavior of Bottlenose Dolphins in the Shannon Estuary, Ireland as Determined through Static Acoustic Monitoring. Journal of Marine Science and Engineering 9:275. doi: 10.3390/jmse9030275

18. Carreira RS, Wagener ADLR (1998) Speciation of sewage derived phosphorus in coastal sediments from Rio de Janeiro, Brazil. Marine Pollution Bulletin 36:818-827. doi: 10.1016/S0025-326X(98)000629

19. Castelo WFL, Martins MVA, de Lima Ferreira PA, Figueira R, da Costa CF, da Fonseca LB, Bergamashi S, Pereira E, Terroso D, Pinto AFS, Simon MB, Socorro OAA, Frontalini F, da Silva LC, Rocha F, Geraldes M, Guerra JV (2021) Long-term eutrophication and contamination of the central area of Sepetiba Bay (SW Brazil). Environmental Monitoring and Assessment 193:100. doi: 10.1007/s10661-021-08861-1

20. Cobarrubia-Russo S, Barreto G, Quintero-Torres E, Molero-Lizarraga A, Wang X (2019) Occurrence, abundance, range, and residence patterns of Tursiops truncatus on the coast of Aragua, Venezuela. Mammal Research 64:289-297. doi: 10.1007/s13364-018-0401-1

21. Costa APB, Rosel PE, Daura-Jorge FG, Simões-Lopes PC (2016) Offshore and coastal common bottlenose dolphins of the western South Atlantic face-to-face: What the skull and the spine can tell us. Marine Mammal Science 32:1433-1457. doi: 10.1111/mms.12342 
22. Cremer MJ, Daura-Jorge FG, Cypriano-Souza AL, Wedekin LL (2018) Movements of offshore bottlenose dolphins in the South Brazil Bight, Southeastern Brazil. Abstracts of the XII Congreso de la Sociedad Latinoamericana de Especialistas en Mamíferos Acuáticos - RT 18103.

23. de Rock P, Elwen S, Roux J, Leeney R, James B, Visser V, Martin M, Gridley T (2019) Predicting largescale habitat suitability for cetaceans off Namibia using MinxEnt. Marine Ecology Progress Series 619:149-167. doi: 10.3354/meps 12934

24. di Tullio JC, Gandra TBR, Zerbini AN, Secchi ER (2016) Diversity and Distribution Patterns of Cetaceans in the Subtropical Southwestern Atlantic Outer Continental Shelf and Slope. PLOS ONE 11:e0155841. doi: 10.1371/journal.pone.0155841

25. Duarte CSL, Viana AR (2007) Santos Drift System: stratigraphic organization and implications for late Cenozoic palaeocirculation in the Santos Basin, SW Atlantic Ocean. Geological Society, London, Special Publications 276:171-198. doi: 10.1144/GSL.SP.2007.276.01.09

26. Erbe C, Marley SA, Schoeman RP, Smith JN, Trigg LE, Embling CB (2019) The Effects of Ship Noise on Marine Mammals - A Review. Frontiers in Marine Science. doi: 10.3389/fmars.2019.00606

27. Fielding AH, Bell JF (1997) A review of methods for the assessment of prediction errors in conservation presence/absence models. Environmental Conservation 24:38-49. doi: 10.1017/S0376892997000088

28. Fiperj (2020) Projeto de Monitoramento da Atividade Pesqueira na Bacia de Santos (PMAP-BS). https://www.comunicabaciadesantos.com.br/programa-ambiental/projeto-de-monitoramento-daatividade-pesqueira-pmap.html. Accessed 6 May 2021

29. Forcada J (2018) Distribution. In: Wursig B, Thewissen JGM, Kovacs K (eds) Encyclopedia of Marine Mammals, 3rd edn. Elsevier, London, pp 259-262

30. Fruet PF, Secchi ER, di Tullio JC, Kinas PG (2011) Abundance of bottlenose dolphins, Tursiops truncatus (Cetacea: Delphinidae), inhabiting the Patos Lagoon estuary, southern Brazil: implications for conservation. Zoologia (Curitiba) 28:23-30. doi: 10.1590/S1984-46702011000100004

31. Guerra M, Dawson S, Brough T, Rayment W (2014) Effects of boats on the surface and acoustic behaviour of an endangered population of bottlenose dolphins. Endangered Species Research 24:221236. doi: 10.3354 /esr00598

32. Guisan A, Thuiller W, Zimmermann NE (2017) Habitat Suitability and Distribution Models. Cambridge University Press, Cambridge

33. Habel JC, Hillen J, Schmitt T, Fischer C (2016) Restricted movements and high site fidelity in three East African cloud-forest birds. Journal of Tropical Ecology 32:83-87. doi: 10.1017/S0266467415000516

34. Halpern BS, Frazier M, Potapenko J, Casey KS, Koenig K, Longo C, Lowndes JS, Rockwood RC, Selig ER, Selkoe KA, Walbridge S (2015) Spatial and temporal changes in cumulative human impacts on the world's ocean. Nature Communications 6:7615. doi: 10.1038/ncomms8615

35. Hammond PS, Mizroch SA, Donovan GP (1990) Individual recognition of cetaceans: use of photoidentification and other techniques to estimate population parameters. Cambridge

36. IBGE (2010) Censo 2010. https://censo2010.ibge.gov.br/. Accessed 9 May 2021 
37. Ingram S, Rogan E (2002) Identifying critical areas and habitat preferences of bottlenose dolphins Tursiops truncatus. Marine Ecology Progress Series 244:247-255. doi: 10.3354/meps244247

38. Knip DM, Heupel MR, Simpfendorfer CA (2012) Habitat use and spatial segregation of adult spottail sharks Carcharhinus sorrah in tropical nearshore waters. Journal of Fish Biology 80:767-784. doi: 10.1111/j.1095-8649.2012.03223.x

39. Laporta P, Martins CCA, Lodi L, Domit C, Vermeulen E, di Tullio JC (2017) Report of the working group on habitat use of Tursiops truncatus in the Southwest Atlantic Ocean. Latin American Journal of Aquatic Mammals 11:47-61. doi: 10.5597/00215

40. Lodi L, Cantor M, Daura-Jorge FG, Monteiro-Neto C (2014) A missing piece from a bigger puzzle: declining occurrence of a transient group of bottlenose dolphins off Southeastern Brazil. Marine Ecology 35:516-527. doi: 10.1111/maec.12108

41. Lodi L, Domit C, Laporta P, di Tullio JC, Martins CCA, Vermeulen E (2017) Report of the Working Group on the Distribution of Tursiops truncatus in the Southwest Atlantic Ocean. Latin American Journal of Aquatic Mammals 11:29-46. doi: 10.5597/lajam00214

42. Magris RA, Costa MDP, Ferreira CEL, Vilar CC, Joyeux J, Creed JC, Copertino MS, Horta PA, Sumida PYG, Francini-Filho RB, Floeter SR (2021) A blueprint for securing Brazil's marine biodiversity and supporting the achievement of global conservation goals. Diversity and Distributions 27:198-215. doi: $10.1111 /$ ddi. 13183

43. Marins FO, Novaes RLM, Rocha RM, Junqueira AOR (2010) Non indigenous ascidians in port and natural environments in a tropical Brazilian bay. Zoologia (Curitiba) 27:213-221. doi: 10.1590/S198446702010000200009

44. Marley SA, Salgado Kent CP, Erbe C, Parnum IM (2017) Effects of vessel traffic and underwater noise on the movement, behaviour and vocalisations of bottlenose dolphins in an urbanised estuary. Scientific Reports 7:13437. doi: 10.1038/s41598-017-13252-z

45. Mazzoil M, Reif JS, Youngbluth M, Murdoch ME, Bechdel SE, Howells E, McCulloch SD, Hansen LJ, Bossart GD (2008) Home Ranges of Bottlenose Dolphins (Tursiops truncatus) in the Indian River Lagoon, Florida: Environmental Correlates and Implications for Management Strategies. EcoHealth 5:278-288. doi: 10.1007/s10393-008-0194-9

46. McBride-Kebert S, Taylor JS, Wilkinson KA, Lyn H, Moore FR, Sacco DF, Kar B, Kuczaj II SA (2019) Common Bottlenose Dolphin, Tursiops truncatus, Seasonal Habitat Use and Associations with Habitat Characteristics in Roanoke Sound, North Carolina. International Journal of Comparative Psychology. doi: 10.46867/ijcp.2019.32.02.01

47. Melo-Merino SM, Reyes-Bonilla H, Lira-Noriega A (2020) Ecological niche models and species distribution models in marine environments: A literature review and spatial analysis of evidence. Ecological Modelling 415:108837. doi: 10.1016/j.ecolmodel.2019.108837

48. Milmann L, Danilewicz D, Machado R, Santos RA dos, Ott PH (2016) Feeding ecology of the common bottlenose dolphin, Tursiops truncatus, in southern Brazil: analyzing its prey and the potential overlap with fisheries. Brazilian Journal of Oceanography 64:415-422. doi: 10.1590/s1679-

87592016116406404

Page 12/19 
49. Morris WF, Doak DF (2002) Quantitative conservation biology: Theory and practice of population viability analysis. Sinauer Associates, Sunderland

50. Moura JF, Siciliano S, Sarcinelli PN, Hacon S (2009) Organochlorine pesticides in marine tucuxi dolphin milk incidentally captured with its calf in Barra de São João, east coast of Rio de Janeiro State, Brazil. Marine Biodiversity Records 2:e62. doi: 10.1017/S1755267209000530

51. Naimi B, Hamm NAS, Groen TA, Skidmore AK, Toxopeus AG (2014) Where is positional uncertainty a problem for species distribution modelling? Ecography 37:191-203. doi: 10.1111/j.16000587.2013.00205.x

52. Nathan R, Getz WM, Revilla E, Holyoak M, Kadmon R, Saltz D, Smouse PE (2008) A movement ecology paradigm for unifying organismal movement research. Proceedings of the National Academy of Sciences 105:19052-19059. doi: 10.1073/pnas.0800375105

53. Pace DS, di Marco C, Giacomini G, Ferri S, Silvestri M, Papale E, Casoli E, Ventura D, Mingione M, Alaimo Di Loro P, Jona Lasinio G, Ardizzone G (2021) Capitoline Dolphins: Residency Patterns and Abundance Estimate of Tursiops truncatus at the Tiber River Estuary (Mediterranean Sea). Biology 10:275. doi: 10.3390/biology 10040275

54. Passadore C, Möller L, Diaz-Aguirre F, Parra GJ (2018) High site fidelity and restricted ranging patterns in southern Australian bottlenose dolphins. Ecology and Evolution 8:242-256. doi: 10.1002/ece3.3674

55. R Core Team (2021) R: A language and environment for statistical computing.

56. Rangel CA, Chaves LCT, Monteiro-Neto C (2007) Baseline assessment of the reef fish assemblage from Cagarras Archipelago, Rio de Janeiro, southeastern Brazil. Brazilian Journal of Oceanography 55:7-17. doi: 10.1590/S1679-87592007000100002

57. Redfern J, Ferguson M, Becker E, Hyrenbach K, Good C, Barlow J, Kaschner K, Baumgartner M, Forney K, Ballance L, Fauchald P, Halpin P, Hamazaki T, Pershing A, Qian S, Read A, Reilly S, Torres L, Werne F (2006) Techniques for cetacean-habitat modeling. Marine Ecology Progress Series 310:271-295. doi: 10.3354/meps310271

58. Reis AT, Maia RMC, Silva CG, Rabineau M, Guerra JV, Gorini C, Ayres A, Arantes-Oliveira R, Benabdellouahed M, Simões I, Tardin R (2013) Origin of step-like and lobate seafloor features along the continental shelf off Rio de Janeiro State, Santos basin-Brazil. Geomorphology 203:25-45. doi:

10.1016/j.geomorph.2013.04.037

59. Ribeiro-Campos A, Pereira KS, Quintana CEP, Barbosa M, Dias CP, Brião JA, dos Santos CVC, Castro C, Pedreira HS, Carvalho RR, Santos-Neto E, Bittencourt L, Bisi TL, Lailson-Brito J, Azevedo AF (2021) Habitat use by the Guiana dolphin (Sotalia guianensis) (Cetartiodactyla: Delphinidae) in southeastern Brazil. Regional Studies in Marine Science 44:101778. doi: 10.1016/j.rsma.2021.101778

60. Robinson LM, Elith J, Hobday AJ, Pearson RG, Kendall BE, Possingham HP, Richardson AJ (2011) Pushing the limits in marine species distribution modelling: lessons from the land present challenges and opportunities. Global Ecology and Biogeography 20:789-802. doi: 10.1111/j.14668238.2010.00636.x

61. Rodrigues A, Pilgrim J, Lamoreux J, Hoffmann M, Brooks T (2006) The value of the IUCN Red List for conservation. Trends in Ecology \& Evolution 21:71-76. doi: 10.1016/j.tree.2005.10.010 
62. Rohlf FJ (1970) Adaptive Hierarchical Clustering Schemes. Systematic Biology 19:58-82. doi: 10.1093/sysbio/19.1.58

63. Sbrocco EJ, Barber PH (2013) MARSPEC: ocean climate layers for marine spatial ecology. Ecology 94:979-979. doi: 10.1890/12-1358.1

64. Schoeman RP, Patterson-Abrolat C, Plön S (2020) A Global Review of Vessel Collisions With Marine Animals. Frontiers in Marine Science. doi: 10.3389/fmars.2020.00292

65. Simões-Lopes P, Daura-Jorge F, Lodi L, Bezamat C, Costa A, Wedekin L (2019) Bottlenose dolphin ecotypes of the western South Atlantic: the puzzle of habitats, coloration patterns and dorsal fin shapes. Aquatic Biology 28:101-111. doi: 10.3354/ab00712

66. Simões-Lopes PC, Fabian ME (1999) Residence patterns and site fidelity in bottlenose dolphins, Tursiops truncatus (Montagu) (Cetacea, Delphinidae) off Southern Brazil. Revista Brasileira de Zoologia 16:1017-1024. doi: 10.1590/S0101-81751999000400012

67. Sims DW, Southall EJ, Humphries NE, Hays GC, Bradshaw CJA, Pitchford JW, James A, Ahmed MZ, Brierley AS, Hindell MA, Morritt D, Musyl MK, Righton D, Shepard ELC, Wearmouth VJ, Wilson RP, Witt MJ, Metcalfe JD (2008) Scaling laws of marine predator search behaviour. Nature 451:1098-1102. doi: $10.1038 /$ nature06518

68. Smith AG, Gangolli SD (2002) Organochlorine chemicals in seafood: occurrence and health concerns. Food and Chemical Toxicology 40:767-779. doi: 10.1016/S0278-6915(02)00046-7

69. Tardin RH, Simão SM, Alves MAS (2013) Distribution of Tursiops truncatus in Southeastern Brazil: a Modeling Approach for Summer Sampling. Natureza \& Conservação 11:65-74. doi: 10.4322/natcon.2013.011

70. Tardin RH, Chun Y, Jenkins CN, Maciel IS, Simão SM, Alves MAS (2019) Environment and anthropogenic activities influence cetacean habitat use in southeastern Brazil. Marine Ecology Progress Series 616:197-210. doi: 10.3354/meps12937

71. Tardin RH, Maciel IS, Maricato G, Simão SM, Maria TF, Alves MAS (2020) Occurrence, residency patterns and habitat use of the bottlenose dolphin, Tursiops truncatus truncatus, on two Marine Protected Areas in Southeastern Brazil. Anais da Academia Brasileira de Ciências 92:e20180843. doi: 10.1590/0001-3765202020180843

72. Teixeira CR, Botta S, Daura-Jorge FG, Pereira LB, Newsome SD, Simões-Lopes PC (2021) Niche overlap and diet composition of three sympatric coastal dolphin species in the southwest Atlantic Ocean. Marine Mammal Science 37:111-126. doi: 10.1111/mms.12726

73. Thuiller W, Georges D, Engler R, Breiner F (2020) biomod2: Ensemble Platform for Species Distribution Modeling.

74. Tubino R de A, Monteiro-Neto C, Moraes LE de S, Paes ET (2007) Artisanal fisheries production in the coastal zone of Itaipu, Niterói , RJ, Brazil. Brazilian Journal of Oceanography 55:187-197. doi: 10.1590/S1679-87592007000300003

75. Tucker MA, Ord TJ, Rogers TL (2014) Evolutionary predictors of mammalian home range size: body mass, diet and the environment. Global Ecology and Biogeography 23:1105-1114. doi:

$10.1111 /$ geb.12194

Page $14 / 19$ 
76. van Waerebeek K, Baker AN, Félix F, Gedamke J, Iñiguez M, Sanino GP, Secchi E, Sutaria D, van Helden A, Wang $Y$ (2007) Vessel collisions with small cetaceans worldwide and with large whales in the Southern Hemisphere, an initial assessment. Latin American Journal of Aquatic Mammals. doi:

10.5597/lajam00109

77. Vidal LG, Vannuci-Silva M, Alonso MB, Feo ML, Corcellas C, Bisi TL, Flach L, Fragoso ABL, Lima Silva FJ, Carvalho VL, de Meirelles ACO, Domit C, Barbosa LA, Cremer MJ, Azevedo AF, Torres JPM, Malm O, Lailson-Brito J, Eljarrat E (2020) Pyrethroid insecticides along the Southwestern Atlantic coast: Guiana dolphin (Sotalia guianensis) as a bioindicator. Science of The Total Environment 728:138749. doi: 10.1016/j.scitotenv.2020.138749

78. Walker TR, Adebambo O, del Aguila Feijoo MC, Elhaimer E, Hossain T, Edwards SJ, Morrison CE, Romo J, Sharma N, Taylor S, Zomorodi S (2019) Environmental Effects of Marine Transportation. In: World Seas: an Environmental Evaluation. Elsevier, pp 505-530

79. Warkentin IG, Hernández D (1996) The conservation implications of site fidelity: A case study involving nearctic-neotropical migrant songbirds wintering in a Costa Rican mangrove. Biological Conservation 77:143-150. doi: 10.1016/0006-3207(95)00146-8

80. Wedekin LL, Daura-Jorge FG, Simões-Lopes PC (2004) An Aggressive Interaction Between Bottlenose Dolphins (Tursiops truncatus) and Estuarine Dolphins (Sotalia guianensis) in Southern Brazil. Aquatic Mammals 30:391-397. doi: 10.1578/AM.30.3.2004.391

81. Zanardo N, Parra GJ, Möller LM (2016) Site fidelity, residency, and abundance of bottlenose dolphins (Tursiops sp.) in Adelaide's coastal waters, South Australia. Marine Mammal Science 32:1381-1401. doi: 10.1111/mms.12335

82. Zanardo N, Parra GJ, Passadore C, Möller LM (2017) Ensemble modelling of southern Australian bottlenose dolphin Tursiops sp. distribution reveals important habitats and their potential ecological function. Marine Ecology Progress Series 569:253-266. doi: 10.3354/meps12091

83. Zolman ES (2002) Residence patterns of bottlenose dolphins (Tursiops truncatus) in the Stono River Estuary, Charleston County, South Carolina, U.S.A. Marine Mammal Science 18:879-892. doi: 10.1111/j.1748-7692.2002.tb01079.x

84. Zurell D, Franklin J, König C, Bouchet PJ, Dormann CF, Elith J, Fandos G, Feng X, Guillera-Arroita G, Guisan A, Lahoz-Monfort JJ, Leitão PJ, Park DS, Peterson AT, Rapacciuolo G, Schmatz DR, Schröder B, Serra-Diaz JM, Thuiller W, Yates KL, Zimmermann NE, Merow C (2020) A standard protocol for reporting species distribution models. Ecography 43:1261-1277. doi: 10.1111/ecog.04960

85. Zuur AF, leno EN, Elphick CS (2010) A protocol for data exploration to avoid common statistical problems. Methods in Ecology and Evolution 1:3-14. doi: 10.1111/j.2041-210X.2009.00001.x

\section{Tables}

Table 1 Data source of environmental and anthropogenic layers used as explanatory variables to model the suitable areas for common bottlenose dolphin (Tursiops truncatus truncatus) occurrence in Rio de Janeiro State. 
Layers

References

Environmental

\begin{tabular}{ll}
\hline Bathymetry & MARSPEC \\
\hline Current velocity (minimum, mean and maximum) & Bio-ORACLE \\
\hline Distance to coast & GMED \\
\hline Primary productivity (minimum, mean and maximum) & Bio-ORACLE \\
\hline Salinity & Bio-ORACLE \\
\hline Sea surface temperature (minimum, mean and maximum) & Bio-ORACLE \\
\hline Seabed slope & GMED \\
\hline Anthropogenic & \\
\hline Port activities (ocean-based pollution) & Halpern et al.
\end{tabular}

Table 2 Summary statistics of distribution modeling of common bottlenose dolphin (Tursiops truncatus truncatus) in the Rio de Janeiro State, Brazil. This includes evaluation scores of each algorithm and ensemble, importance of each variable and number of models of each algorithm in the ensemble model.

\begin{tabular}{lllllllll} 
Algorithms & $\begin{array}{l}\text { Evaluation } \\
\text { scores }\end{array}$ & \multicolumn{2}{l}{ Variable Importance } & & & & & $\begin{array}{c}\text { Models in } \\
\text { ensemble }\end{array}$ \\
\cline { 2 - 6 } & pAUC & CURmin & CURmax & Port & PPmin & Slope & SSTmin & \\
\hline GLM & 0.79 & 0.05 & 0.04 & 0.03 & 0.68 & 0.29 & 0.06 & 35 \\
\hline GAM & 0.78 & 0.07 & 0.05 & 0.08 & 0.82 & 0.33 & 0.04 & 27 \\
\hline RF & 0.79 & 0.06 & 0.10 & 0.22 & 0.39 & 0.14 & 0.23 & 42 \\
\hline GBM & 0.81 & 0.05 & 0.05 & 0.03 & 0.75 & 0.16 & 0.08 & 38 \\
\hline FDA & 0.76 & 0.03 & 0.34 & 0.24 & 0.15 & 0.07 & 0.18 & 24 \\
\hline MaxEnt & 0.79 & 0.02 & 0.08 & 0.04 & 0.99 & 0.12 & 0.01 & 41 \\
\hline Ensemble & 0.79 & 0.05 & 0.10 & 0.10 & 0.65 & 0.18 & 0.10 & 207
\end{tabular}

Abbreviations: GLM = Generalized Linear Models; GAM = Generalized Additive Models; RF = Random Forest; GBM = Generalized Boosting Model; FDA = Flexible Discriminant Analysis; MaxEnt $=$ Maximum Entropy; pAUC $=$ partial Area Under a Curve; CURmin $=$ Current velocity $($ minimum); CURmax $=$ Current velocity $($ maximum); Port $=$ Port activities (proximity to port complexes and shipping routes); PPmin = Primary Productivity (minimum); Slope = Seabed slope; SSTmin $=$ Sea surface temperature (minimum) . 
Figures
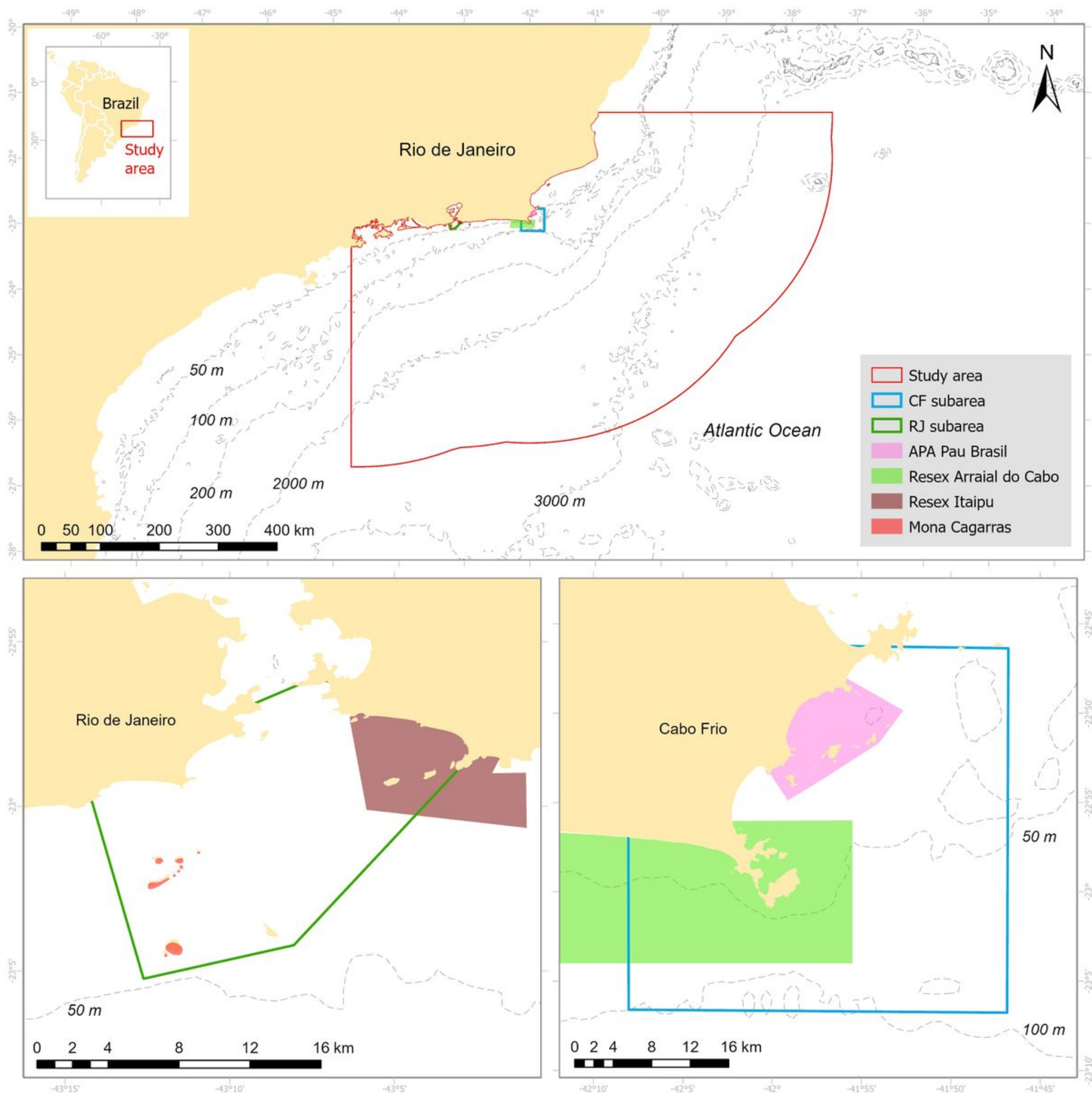

\section{Figure 1}

Study area encompassing the coastal limits of Rio de Janeiro State, Southeastern Brazil, subareas of Cabo Frio (CF) and Rio de Janeiro (RJ), and marine protected areas located in Rio de Janeiro, Brazil. APA Pau Brasil = Área de Proteção Ambiental do Pau Brasil (IUCN category VI); Resex Arraial do Cabo $=$ Reserva Extrativista Marinha do Arraial do Cabo (IUCN category V); Resex Itaipu = Reserva Extrativista Marinha de 
Itaipu (IUCN category V); Mona Cagarras = Monumento Natural das IIhas Cagarras (IUCN category III). For more details on categories, see Day et al. (2019, http://dx.doi.org/10.25607/OBP-694).

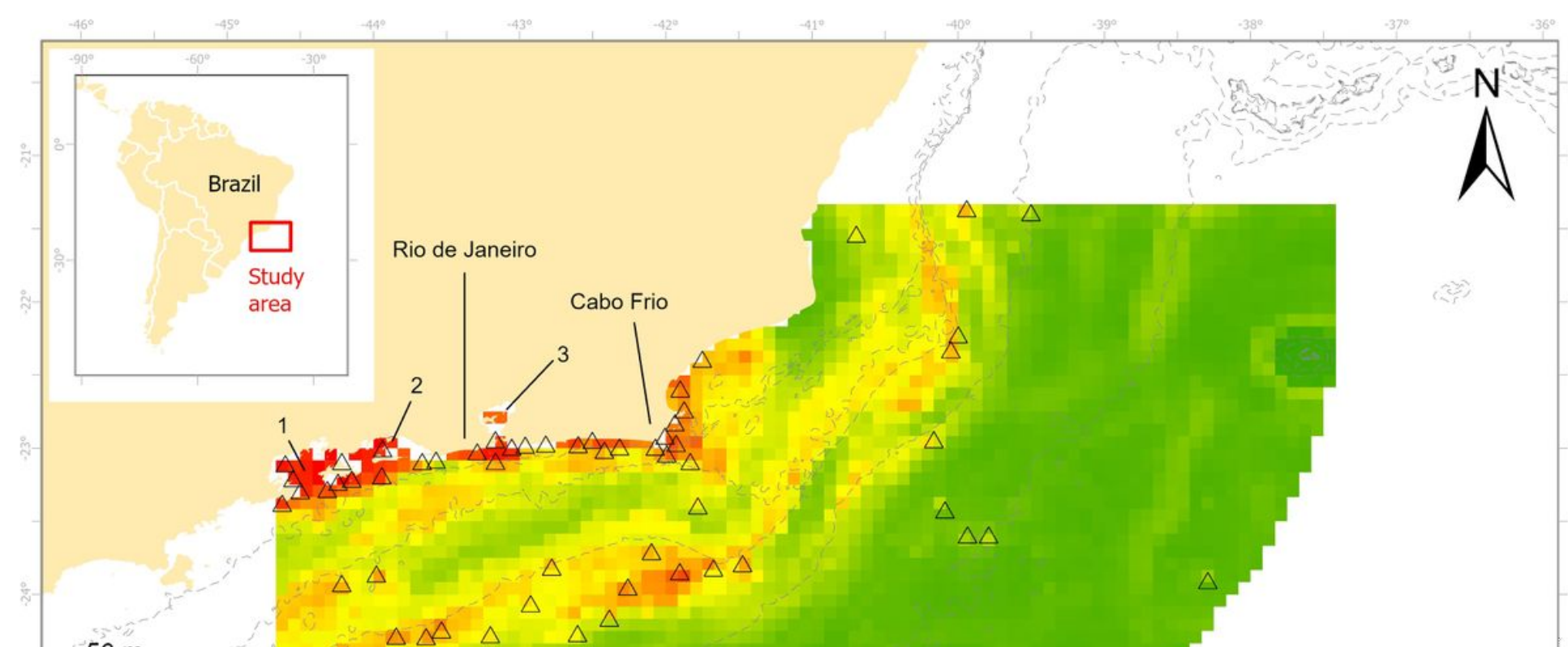

\section{Figure 2}

Habitat suitability calculated by weighted mean for the common bottlenose dolphin, Tursiops truncatus truncatus, in Rio de Janeiro, Brazil. 1 = Ilha Grande bay; 2 = Sepetiba bay; 3 = Guanabara bay.

\section{Supplementary Files}

This is a list of supplementary files associated with this preprint. Click to download.

- SupplementaryFigure1a.jpg

- SupplementaryFigure1b.jpg

- SupplementaryFigure1c.jpg

- SupplementaryFigure2.jpg

- SupplementaryFigure3.jpg 
- SupplementaryTable1.docx

- SupplementaryTable2.docx 